\title{
DOMESTICATING DIGITAL GAME-BASED LEARNING
}

by Helga Dís Îsfold Sigurđardóttir

This paper analyses the use of digital game-based learning (DGBL) in schools in Norway. It investigates the types of games used in Norwegian schools and how pupils experience that practice. Digital game-based learning is being widely employed throughout Norway as a result of the increased focus on digital skills in Norwegian education. This paper analyses that development by way of focus group interviews with a total of sixty-four pupils at four schools. Drawing upon domestication and actor-network theory, the paper provides a novel approach to the study of DGBL. The broad empirical investigation into $D G B L$ practices furthermore provides a contribution to scholarly literature on the subject. A noteworthy finding of this study is the diversity of games employed in schools-around 30 different titles - indicating that the choice of games lies at the discretion of individual teachers. Findings from this research show that the domestication of digital game-based learning occurs through the construction of complex game-based learning assemblages. This includes the classroom and home as gaming sites, group work and individual assignments as practices, and PCs and iPads as platforms.

Keywords: Author: 


\section{Introduction: an evolving technology for education}

This paper focuses on the use of digital game-based learning (DGBL) in Norwegian schools, the types of games employed, how they are used, and how pupils experience these practices. The growing reputation of DGBL has given this topic increased scholarly and political attention. The theoretical analysis and broad empirical investigation into DGBL practices serve as an important contribution to this growing body of literature as well as to the field of science and technology studies and domestication theory.

How has the use of digital games in educational settings been analysed? For starters, games vary in many ways, including design, size, graphics, content, context, and storyline (Egenfeldt-Nielsen 2006). Scholarly studies have made an important distinction between games designed for entertainment and those designed for education. In this paper I refer to entertainment games as commercial games, while those designed for education are termed educational games. The term digital game-based learning (DGBL) comprises any employment of digital games in education.

Numerous scholars have noted that digital games have been received with varying degrees of enthusiasm. When DGBLpioneers began actively promoting digital games as potential learning tools, these games had already been widely labelled as potentially harmful to players (Gee 2012, Skancke 2013, Sigurðardóttir et al. 2013). In Norway, digital games saw a political breakthrough in 2007 when they became the central topic of "The Competence Reform Report". In spite of the report's lack of focus on DGBL, its emphasis on games as an important cultural medium was a significant moment in the introduction of digital games to school settings (Skancke 2013, St. meld. no. 14 (2007-2008)).

Some prominent voices and initiatives have suggested replacing traditional teaching tools and methods with DGBL. Most DGBL discourse, however, revolves around digital games as supplements to, rather than substitutes for, other teaching tools and methods. Most pupils currently within the educational system are already accustomed to digital games. In 2014, a Norwegian survey found that ninety-four percent of children between the ages of nine and sixteen play digital games in their free time at home and during breaks at school (Medietilsynet 2014). Although many young people interact with friends through online games, scholars disagree about the desirability of such socialization. Playing digital games with one another when physically together is also common (Steinkuehler 2012, Prensky 2006, Barab et al. 2012).

Children may find game-playing for the sake of learning quite different from playing for entertainment, and this too varies between schools and programmes. The use of DGBL is seen as a challenge for schools, staff, and the curriculum. Steinkuehler (2012: 62) claims that both teachers and parents "typically loathe video gaming" and that handheld devices for game playing are "an unwanted sight in school hallways, let alone classrooms". The general acknowledgement of the game medium by Norwegian authorities suggests, however, that this might be changing (St. meld. no. 14 (2007-2008)). Be this as it may, the negative characterisation of games in public discourse is considered an obstacle for the implementation of DGBL in schools (Van Eck 2006, Skancke 2013).

Digital games have, for example, been studied in eLearning environments as well as in classroom settings. Some of these studies have focused on groups, others on individual play. DGBL may also include, among other elements, group discussions and gaming homework (Barab et al. 2012, McGonigal 2011, Moreno-Ger et al. 2009, Gerber et al. 2014). Motivation, both intrinsic and extrinsic, is a key concept in DGBL. Intrinsic motivation refers to learning processes wherein the pride in, or joy of, the task itself is the key motivator. Extrinsic motivation is based on external reward or reinforcement (Dickey 2007, Schunk 2009, Lei 2010). Playing a digital game is often intrinsically motivated and the results extrinsic. In fact, many see intrinsic motivation as the most important educational aspect of digital games. Intrinsic rewards such as challenge, control, choice, and achievement are argued to be elements that keep the players motivated. The design of educational games has come under scrutiny for failing to highlight intrinsic motivation factors. Critics claim that, building on extrinsic motivation, DGBL simply disguises traditional teaching methods in an attractive suit (Whitton 2010, Lei 2010, Dickey 2007, Prensky 2006, Resnick 2004). In this sense the term 'chocolate covered broccoli' is employed to suggest that the learning part of the experience is not enjoyable in and of itself (Habgood 2007).

Some are sceptical of the practical aspect motivation plays in educational games: "There's a vast difference between a game that educates a player, and a game that requires a player to be educated" (Creighton 2012). Some games actually teach players skills that they did not have previously, while others focus on players' extant knowledge. The latter are often referred to as drilling games, Creighton calls them 'quizzes' (2012).

While the body of research on DGBL has grown in recent years, there are notable and persistent shortcomings in those scholarly studies. To offer an idea of these: a recent search for the term 'DGBL' in the Academic Search Premier database resulted in just 21 relevant academic texts. Thirteen of these relied primarily on quantitative methods - although some also utilized qualitative methods, most of those either tested games or interventions, or described controlled experiments. Six of the texts were purely theoretical and two were metaanalyses. Of the articles that offered empirical data, the majority focused on narrowly defined age groups. These results suggest that there is a real need for more broadly conceived studies of DGBL practices. This paper is an effort to address this deficiency by analysing how $8-18$ year old pupils experience DGBL in Norwegian schools. But how can we analyse this situation? 


\section{Making sense of digital game-based learning}

This paper analyses the practice of DGBL through the application of domestication theory and actor-network theory (ANT). While these two theories are clearly related and share significant assumptions they have useful differences in terms of focus. Domestication theory refers to the process of habituation through which a new object changes from unknown to known. The theory initially focused on providing contextual information for the household adaptation and application of information and communication technology (ICT), including new media technologies (Sørensen 2006, Liste and Sørensen 2015, Haddon 2011). Since, the focus has widened to refer to any consumption actor or unit-such as, for instance, local governments (Berker et al. 2006, Liste and Sørensen 2015) or, as is the case in this paper, schools, and pupils.

Domestication theory developed out of the media research of Roger Silverstone and his collaborators in the early 1990s. Because this paper pursues a set of issues related to technology studies, I make use of the so-called 'Trondheim model', which is a version drawing on insight from science and technology studies. It presents the process of domestication as consisting of three aspects: the practical, the symbolic, and the cognitive. One focuses on the development of user practice in the uptake of a new technology into everyday life and the resultant patterns of use and routine established in a given context. A second, the symbolic aspect, covers sense-making activities related to that new technology, while the third cognitive aspect refers to the learning involved in adapting to a new technology and developing new ways of understanding and use (Sørensen et al. 2000, Sørensen 2006).

With a focus on the assembly of actor networks, Actor-network theory assigns agency to technology as well as humans. Thus, an actor-network usually consists of both human and nonhuman actors. When viewed through the lens of ANT, non-human objects - like a key ring or a computer - are considered actors that affect socio-technical activity (Giddings 2005, Sørensen 2004, Latour 2003, 2005). When the research topic is DGBL, it can be useful to approach digital game software and the equipment used to play games as active objects that influence other actors.

Latour (2005) introduces 'assemblage' and 'assembling' as conceptual tools. Assemblage has previously been used to reflect on the complexity of digital games (Taylor, 2010). Playing a digital game is enacting a network of interrelated systems. The resultant assemblage is a collection or a process of linking people and things as well as their connections and interactions. Latour finds this concept more accurate than what is often simply referred to as 'social' or 'society'. The topic of analysis then becomes "the work of making associations" (Liste \& Sørensen 2015). How does this come about in the enactment of DGBL?

My analysis also draws on Madeleine Akrich's (1992) concept of script. She is concerned with the role of designers in scripting technological objects when they build heterogeneous networks in specific ways by affording certain connections between actants of various shapes and sizes - non-human as well as human - as an effort to shape how the objects are used. Thus, Akrich's argument is that designers attempt to inscribe what they consider to be anticipated user actions into the artefacts they construct. This also implies that they try, in this manner, to shape the way in which artefacts are domesticated through, for example, the actions required to make a piece of technology 'work'. Like other designers, game designers try to predetermine - technically and socially - how their games are played. Educational games are, for example, often designed differently than entertainment games (Whitton 2010, Prensky 2006, Creighton 2012, Gee 2013). This does not mean that the actual domestication follows a given script. This has to be analysed empirically.

Ask claims that the scripting of a game restricts and directs users' redesign when a particular game is enacted: "Artifacts are not empty objects, waiting to be filled with the users' meanings. In the design process, ideas about use and users are scripted into the design and materialized" (2011: 144). She goes on to say that although design can be domesticated in many ways, the script usually plays a central role in shaping the development of players' routines. Here, we shall study the extent to which scripts may be identified in interviewees' accounts of their own encounters with DGBL. To summarize, domestication theory will be used to explore and characterize the practices with respect to DGBL and related sense-making. This includes pupils' understanding of and attitudes toward DGBL. Actornetwork theory will be used to analyze how actual DGBL practices are assembled. Finally, the script concept will be used as a point of departure for discussing the extent to which the digital games used in DGBL practices shape the afore mentioned practices.

\section{Method: Studying DGBL in Norwegian schools}

Norwegian school authorities are, for the most part, fairly open-minded to the use of ICT in teaching. Alongside reading, writing, verbal expression, and mathematics, digital skills are listed as one of the five basic skills in Norwegian schools (ICILS,
2014). ' When representatives of Scandinavian education are compared to their European counterparts and the global situation, they respond somewhat differently from others in regard to DGBL. While others assumed that DGBL would not be a topic for 


\section{N}

NORDIC JOURNAL

of Science and Technology Studies

mainstream adoption for at least two or three more years, the Scandinavian panel "sees games and gamification as a near-term horizon topic" (2015 NMC Technology Outlook: 4). ${ }^{2}$ Norwegian pupils have been named as the second most proficient in a comparison of the digital skills of lower secondary schools in eighteen countries (ICILS 2014). ${ }^{3}$ Several official resources concerning DGBL in Norway are available online, ${ }^{4}$ and thus there was good reason to believe that this study could actually identify and analyse schools using DGBL.

In an effort to pursue this line of inquiry, the present paper is primarily based on sixteen focus group interviews with primary and upper secondary school pupils at four Norwegian schools. Norwegian children begin primary school at the age of six, and move on to lower secondary school from age thirteen to sixteen. Upper secondary school spans three years, and graduation qualifies for higher education. Focus group interviewing has been selected because this technique allows for discussion among pupils and facilitates richer insight into a groups' engagement with assimilation of DGBL.

In order to maintain anonymity, the four schools will be referred to as $A, B, C$, and D, respectively. Three of the schools are situated in two of Norway's largest cities and one in a medium-sized town. School A had an enrolment of roughly three hundred children ranging from first to seventh grade. School $D$ had roughly five hundred pupils ranging from first to tenth grade. Schools B (ca. eight hundred pupils) and $C$ (ca. five hundred pupils) are upper secondary schools. I came into contact with school A through a colleague. Schools B and C made direct contact with me through a 'call for schools' on Twitter and Facebook. My introduction to school $D$ was based on suggestions from pupils at school $C$ who had experienced DGBL while in attendance there. To my knowledge there is no available statistical information on the frequency of DGBL in Norwegian schools and there was nothing special about the schools in my sample other than their use of digital games for teaching. In regard to equipment, school A had struggled with old PCs with limited capacity until they solved the problem by buying two sets of twenty iPads. Schools B, C and D primarily used PCs.

The focus group interviews took place between October 2014 and January 2015. I interviewed sixty-four youngsters in total, and an assistant was present at each interview:

(1) nineteen third-graders at school A (twelve boys, seven girls

(2) thirteen sixth-graders at school D (six boys, seven girls)

(3) twenty upper secondary school first year pupils

(age sixteen) at school C (ten boys, ten girls)

(4) twelve upper secondary school third year pupils (age

2 http://cdn.nmc.org/media/2015-technology-outlook-scan-

dinavian-schools-EN.pdf, accessed May 13, 2015.

3 http://iktsenteret.no/sites/iktsenteret.no/files/attach-

ments/icils-rapport.pdf, accessed May 13, 2015

4 https://iktsenteret.no/prosjekter/dataspill-i-skolen, accessed May 13, 2015 eighteen) at school B (nine boys, three girls)

There were about forty third graders at school A. The teacher sent out information and consent forms to only twenty parents. He disclosed that the chosen twenty were 'reliable respondents', pupils with a 'stable' family background, and generally among the better performing third graders. In school B the teacher gave me free access to a class of twentyseven pupils. I chose to talk to all of the available girls, only three out of the five were present that day and I wanted to make sure that girls' viewpoints were recorded. The rest of the participants were randomly selected from the class list; some volunteered. At school C I was assigned an entire class of twenty pupils. The teacher at school $D$ sent my information and consent forms out to a class of about thirty, but only thirteen responded. She said that the group consisted of varying 'learners'.

All interviews were done in Norwegian, recorded and transcribed verbatim. Seven of the teachers provided additional information by way of phone conversations, informal talks, and e-mail communication, but only one of these exchanges could be considered an interview. This was transcribed along with those of the focus groups. The interview and the information given by the other teachers have been included in the analysis. The coding and the analysis of the transcriptions and the information from the teachers were inspired by grounded theory (Creswell 1998). Several memos and notes were written and processed. I largely depended on NVivo software for coding. In the presentation of results, interviewees have been given names to preserve anonymity: those from school $A$ were given names beginning with an $A$, those from school B starting names beginning with a B, etc.

How do we define a digital game? For practical reasons, when my interviewees called something a digital game, I followed their lead. If teachers refer to something as a digital game, pupils are likely to perceive it as such. The quiz tool Kahoot can serve as an example of what is involved in this process. It is, technically speaking, not a game but a tool to create quizzes. However, it was talked about as a digital game by the interviewees, and this perception affected how the tool was domesticated by the school as well as how its script was experienced by pupils, parents, and other stakeholders. Many educational apps and text book supplement exercises viewed as games by the interviewees would not be accepted as such by all DGBL-scholars, and it was not always clear if the designers of these tools had scripted them as a game or another kind of educational experience. As the benefits of imposing external classifications were uncertain I have chosen to be inclusive and retain local definitions.

The subsequent analysis consists of two sections. I first discuss the types of digital games that were used, in what subjects and how. This section aims at mapping elements that may potentially be part of the DGBL assemblages and exploring aspects of the assembly work by drawing on actor-network theory. The second section analyses how pupils domesticated digital games. 


\section{Digital games in teaching: the what, the where, and the how}

Previous research has found that while children and young people are avid technology users at home, they associate computer use in school with boredom.

The teenagers mainly associated school computing with typing, to gather useful information from the Internet and make presentations. Thus, in their 'official' accounts, ICT was linked to useful tasks which they saw as boring because the tasks allowed no play and fun. By contrast, out of-school computing was mainly constructed as fun, only to a small extent as useful (Gansmo 2011: 114-115).

Does school automatically make all digital activities boring, or can digital games somehow counteract such sense-making? In the following, I discuss features of the digital games that were made part of DGBL assemblages at the four schools. I return to pupils' sense-making in the next section.

Previous research about DGBL offers few clues about what to expect about what games teachers choose to use in their teaching. Given the lack of official models or guidelines, I expected substantial local variation. This was confirmed. In total, more than thirty games, gaming sites, and tools were mentioned during the course of interviews. Aside from the quiz game Kahoot, however, which was used at three of the four schools, there was very little overlap. Each teacher constructed their DGBL assemblage in a fairly idiosyncratic manner and composed complex learning assemblages of methods, approaches, and tools according to her/his own preferences. The choice of games did not appear as accidental but rather as a result of the games with which the teacher was familiar and her/his preferences and teaching practices.

There have been several attempts to define and categorize digital games for learning. For the purposes of this paper, I found it sufficient to distinguish between educational and commercial games. Within the first category, I make a distinction between 1) drill/quiz games, that is, games that test/drill what users already know and 2) exploration games or games that require no previous knowledge of the topic and are scripted to teach something new. Each of these two sub-categories formed the core of two distinctly different DGBL assemblages; a test/drill assemblage and an exploration assemblage. The category of commercial games had less distinct qualities. The main shared feature of games of this variety mentioned by interviewees was their single-player quality. Thus, I simply term the third main DGBL assemblage 'the commercial assemblage.' According to these guidelines the roughly thirty games mentioned during the course of the interviews can be categorized as follows:

(1) Over 20 drill/quiz games

(2) 1-2 exploration games

(3) 6-7 commercial games
One of the games, originally a commercial game but later made available in an 'educational version', could be assigned to either category 2 or 3 .

Each of the mathematics games in the study belonged to the first category, drill/quiz games, and were used only in the primary schools (A and D). These games were assemblages of arithmetic problems, varying in complexity, scripted to test and drill students individually or in competition with others. In school A, the third grade teachers used four math games. All shared a similar structure. An arithmetic problem such as $2+2$ is presented. The player is given a choice between a few answers, such as 2,4 or 6 . The player selects the presumed right answer. If this is correct, a new calculation pops up-along with a new set of answer options.

A storyline or a plot is commonly included in the scripts of educational games for young learners. Unlike most commercial games, in which the script largely is the plot or storyline, the storyline in an educational game often has seemingly little relevance to the topic. A central focus of the script is practicing certain skills or knowledge. The storyline appears as a byproduct, or the chocolate covering the broccoli. The storyline in one of the math games, for instance, revolved around helping a cat through various dangers. In one of these, the cat drifted on a raft at sea. A shark circled an area between the raft and the shore. Each correctly solved arithmetic problem moved the cat a bit closer to land. Ten correct answers brought the cat safely onto shore. With three or more fails, the raft drifted out to sea and disappeared into the horizon (the shark only symbolizes danger). The arithmetic problems remained unrelated to the storyline. Similarly, the player is offered the opportunity to choose an avatar in two of the games, but the design thereof is primarily relegated to a representation of the player on the scoreboard. One game, Math Fight, was a competitive game in which the iPad-screen is divided into two halves facing opposite sides, thus allowing players to face one another. The third graders were fond of this game; one said it was "a little bit difficult ... and a little bit fun".

In school $D$ the sixth graders use the Mangahigh and Abakus mathematic sites. Abakus is a textbook supplement site that includes, among other assignments, drill/quiz games. As Mangahigh was a popular site with numerous mathematical quiz/drill games, I asked the pupils which game they preferred. Most named Sundae Times, where one plays against opponents, either virtual or real. The real opponents can be either classmates or pupils from other schools around the world. The goal is simple: answer as many multiplication problems as possible in ninety seconds. There are no options; players just type their answers quickly.

Digital games were used to teach languages at all the schools, most commonly English and Norwegian. Some pupils in school $\mathrm{C}$ also mentioned Spanish and other languages. The textbook supplement site Stairs was used in both primary schools ( $A$ and $D$ ). Only a few 
of the Stairs exercises have a game-like structure that fits the first category of drill/quiz. In upper secondary school C, five such games were mentioned in relation to English, all of which were freeware.

One of the games used at school C, The Stanley Parable, was originally scripted as a commercial game. Some users saw additional possibilities by interpreting the game in their own way, and it is now formally available for educational as well as entertainment purposes. As such, it would belong in the second category, exploration games. This transformation is a good example of how human actors (players) interact with other human actors (the game designers) through the game and how scripts may be flexible, or not highly directive. In this case, player feedback led to a small modification of the script. As far as I am aware, the storyline remained intact but free access was facilitated for educators. Camilla, aged sixteen, from school C, describes the use of The Stanley Parable in this way:

We have had [The Stanley Parable] in English. And the point is, well there is a narrator voice that narrates, in English, what the main character does. But you have the choice to decide what you should do, so then you can do the opposite of what the voice tells you. I think the main reason why we played it is that there is a lot of English in the game, the narrator voice speaks English the whole time.

Educational games were used in teaching the pupils' first language, Norwegian, at school A. Five quite different games were mentioned, all drill/quiz games. The topics of these were writing skills, vocabulary, sound formation, reading, and rhyming.

Commercial games were only used by the upper secondary schools, B and C. School B was the only school that used solely commercial digital games. When I emailed their teacher, Balder, asking about this choice, he offered two main reasons. First, he chose to teach using games with which he was familiar, and he was best acquainted with commercial games. Second, he did not find educational games very engaging, saying they were "often of poor quality" and therefore of "limited usefulness". He used a commercial game called Skyrim in Norwegian classes to teach literary concepts like 'sublime'. Other commercial games used at school B included The Walking Dead, The Last of Us, Civilization, Portal, and Grand Theft Auto.

The Walking Dead and The Last of Us were employed in classes about religion, spirituality, and ethics mainly to teach ethical concepts. Civilization was used in economics, sociology, English, and Norwegian classes. A few of the students had experienced Portal in their physics class, and GTA was apparently only used to demonstrate the meaninglessness of media violence. This gave the games rather different roles in the ensuing commercial assemblages, for example as tools for illustrating ethical problems or as representations of ways of thinking about economic development.

At the other schools DGBL was dominated by drill/quiz assemblages. In school B, Kahoot, Itslearning, Yedit and other digital tools were furthermore employed to vote democratically between choices when proceeding in the game. In addition to Kahoot, school $C$ also used Geddit and Quizlet for decision-making and drilling. For this category of assemblage, Kahoot was typically employed in school A at the end of the week to test third graders' knowledge of the weekly curriculum. The exploration assemblage was found at school $\mathrm{C}$ where they used the Sim City-like exploration game Byen ('The Town') in social subjects, focusing on economy, taxes, ethics and more.

Two other aspects were also significant in making the DGBLrelated assemblages, suggesting evidence of yet more differences between the four schools. First, there was a difference in contexts of employing DGBL, including the location (site) and method of playing. Each school had distinct context elements that made the DGBL-related assemblages vary in complicity. Some games were played at school and at home, either as homework or by choice. In school A pupils played individually, and primarily during school hours. Playing at home was optional and seemed to be practiced at random. A common approach to commercial game-play in the two secondary schools ( $B$ and $C$ ) was having the entire class watch one common screen while one person at a time, either the teacher or a pupil, ran the control, receiving directions from the whole group. Students voted on choices and 'ethical challenges' that came up during play.

The Walking Dead and The Last of Us were, for example, played in this way. The teacher would also stop the game every now and then to ask about various subject related matters. Furthermore, the same games were assigned as group homework in school B, giving the assemblage a whole new dimension. In some cases pupils also wrote blog posts about what they had learned, which added to the DGBL-related assemblage. Two pupils from school B, Bjørn and Bjarke, elaborated that in at least one subject the pupils 'just played' and then discussed the game afterwards. Bjarke: "Then we were supposed to relate it to the real world".

Both The Walking Dead and The Last of Us were scripted as single player games for entertainment. When an entire class plays together in order to learn about ethical concepts the script is not followed. In school C, Byen was downloaded onto each student's $P C$ to be played first individually and later in groups of four to five students in the sociology class. In school D, pupils primarily played individually. Sometimes the teacher would lead a game on a smartboard and the children would raise their hands to participate. On Mangahigh, the class played as a team, competing with other schools. Each pupil then played individually, but the collected score of each individual is compared to the score of other schools internationally. School D added a new dimension to the context aspects - it was the only school in which several of the participants reported eagerly playing an educational game, Mangahigh, during after school hours.

To summarise, we may say that the DGBL-related assemblages that 


\section{N}

NORDIC JOURNAL

of Science and Technology Studies

were observed at the four schools showed considerable diversity. The most important types of elements that were combined in the assemblages were: type of game, didactic strategies, site of playing and way of playing (individual, in smaller groups, collectively in the class). The number of distinct assemblages that were used was considerable. This was not simply a result of the fairly large number of different digital games in use, but also of the many possible combinations of the three other elements. Whether this diversity should be interpreted as lack of maturity of DGBL or just what one should expect, is difficult to say at this point. The following section focuses on the ways in which the interviewed pupils accounted for their domestication of DGBL and the ensuing assemblages.

\section{Pupils domesticating DGBL: experiences and evaluation}

As previously mentioned, concrete experiences of pupils with the practical sides of DGBL domestication have been given little attention in extant research. An important idea underlying the use of DGBL is that such games should make learning a more positive and meaningful experience. Is this the case? The short answer is yes, pupils generally appreciate DGBL. The longer answer lies in the analysis of students' accounts of the domestication processes, above all their practices and sense-making, including how they feel about this way of learning and how they evaluate the outcome.

To begin with, it should be noted that the pupils' accounts generally suggested that DGBL was domesticated. This is arguably something they have to do, given the fact that teachers set the agenda with respect to educational activities in the classroom. Be that as it may, pupils expressed no resistance to the domestication process, although there were a few sceptical voices. Domestication is sometimes thought of as an individual process (Sørensen 2006). Interestingly, in the school setting, domestication was accounted for as a collective enterprise in at least two ways. First, teachers and pupils were said to interact in the development of practices and sense-making. Second, according to the interviews, the pupils themselves had to domesticate in step. Clearly, the frequently occurring collaborative and competitive interactions required some similarity in domestication for the game playing to function.

As an example of the latter, games were frequently employed as group activities in both of the upper secondary schools B and C, circumventing the script planning for single players. Pupils appreciated this. Christer (age sixteen), from school C, remarked that:

In one of the games we could choose to play alone. But it is of course a bit fun to be with others as well then, because then you can ... often we have different opinions about what to do, and then there will be a discussion about what is best.

Many upper secondary school students mentioned similar advantages of playing in groups, namely that interaction and discussion about progress in the game gave them a richer experience. This was not without challenges. Eighteen-year-old Birgitte claimed homework group playing was difficult to organize. One reason for this was varying knowledge of the game within the group; another was that playing was 'insanely' time-consuming. It was considered challenging for three individuals to find time, "up to four hours in a row", to work together. This also meant that collective domestication, at least in the sense of developing symmetrical practices and skills, had its challenges.

People must be motivated to engage in the domestication of an artefact or a knowledge object. This issue emerged in many of the focus group exchanges when asked why games are used at their school. The following conversation took place between five sixth graders at school D:

Dagny: Because we're supposed to learn, a bit, how to use a PC. Like, when you're doing math-and we're meant to have some fun at school.

Dina: I learn better when I'm playing a game on the PC than when I sit and work with the book.

Dagmar: I also think I learn better when I work with the PC.

Danielle: I agree. I learn better when I am working with the PC than when I just listen to the teachers talk.

Dora: I actually think just the same, because in the book you have to read through the assignment over and over again and you still don't understand it. But on the PC you can find out by yourself and so on. And you get some time-and then you can do it faster and faster and faster...

The views of these 12 year old school D pupils clearly differ fundamentally from the views of the 14 year old students who, according to an older study, found computers boring as soon as they were placed in a school context (Gansmo 2011). Can the key difference between these experiences lie in the fact that the focus in the current study is on digital games rather than computers? And if so, why do games make the use of computers more fun and the domestication of DGBL more motivating?

The argument that digital games offered a welcome break and even an improvement on more traditional teaching methods was often the first to be cited in the interviews. Also, the aspect of competition was frequently mentioned at all the schools. While evaluating the popularity of games was never the goal of this study, interviews showed that certain games/tools were distinctly more popular than others in three of the schools ( $A, C$ and $D$ ). The way favourite learning games were discussed offers additional insight into the aspects of games pupils find enjoyable. It also tells a lot about the contribution of those non-human agents to the learning experience. 


\section{N}

NORDIC JOURNAL

of Science and Technology Studies

In school A, Kahoot was the favourite. It was played on Fridays to summarize and test the knowledge of the weekly curriculum. Kahoot was the first game the interviewees mentioned when asked if they played games in school, and they talked eagerly about their Kahoot experiences. Most of the interviewed pupils had fond memories of how they had, at some point, done well in Kahoot:

Arild (age eight): I remember once being at first place, when there was a spelling question. "How do you write train?" And then I said that train is written with an e at the end. And that's how I ended up in second place.

When asked why they found Kahoot more fun to play than the other games, competition was the leading explanation. Before Kahoot was domesticated in school A parents had feared that it would lead to too much competition. To overcome this critique, teachers let the parents play, and showed them that only the names of the five top scorers were displayed. This led to parental acceptance of Kahoot. Parents thus also have a role to play in the domestication of DGBL at the schools.

Competition was also a primary reason for the popularity of Mangahigh. Eleven out of thirteen school D pupils favoured Mangahigh. As mentioned above, the site is an assemblage of many different learning games. Mangahigh was the only non-human agent in this study that enabled pupils to compete directly with one another as well as with pupils from other schools. The plots and storylines scripted into Mangahigh games vary, but the game that the sixth graders favoured, Sundae Times, was a simple drill/ quiz game. Competing with other schools seemed to be even more important than competing with one another at school D. Although Mangahigh was not required homework, several participants were so motivated that they spent a considerable share of their free time playing Sundae Times. Their teacher noted that the game led to great progress in knowing the multiplication table by heart for those who had struggled. Interviewees reported that the class had achieved second place on the Mangahigh scoreboard. Their strongest opponent was a school in Sweden that had been in lead for some time. Mangahigh, a non-human agent, was important to the class as not only a learning facilitator, but also in boosting team spirit. It connected the Norwegian sixth graders to their peers in other countries and with one another. The game allowed for competition between classmates and, more importantly, for teambuilding through competition with classes from abroad. A competition-oriented practice may thus be a distinct outcome of the domestication process of DGBL.

This great interest in an educational game was unique among the schools. The majority of the interviewees expressed preference for entertainment games as opposed to educational games during their free time. As a result of its popularity Mangahigh was also used to motivate pupils to finish other, less engaging, school games, like 'the county game', a quiz about Norway's counties that had been made by the teachers. David (age eleven) said:
Many are interested in Mangahigh, so when we played that county-game, we got to choose; if we managed to complete it three times in a row, we got to play Mangahigh. And then everyone was eager to complete it.

Only two of the thirteen pupils, Daisy and Dalia, expressed scepticism about Mangahigh. While Dalia said she loved mathematics, her scepticism was directed at digital games in general. She complained that sitting at the computer made her eyes and shoulders ache. Daisy, on the other hand, said that she disliked mathematics and experienced stress as a result of the time limits imposed by Mangahigh.

No. I don't like mathematics. But I try as hard as I can. I just feel that it becomes too stressful since Mangahigh is timed-and I'm not particularly good at doing things when they're timed, I get stressed really fast, it happens fast-so then I write quite a lot of wrong things, and I don't think that's any fun.

Regardless of such criticism, the two youngest groups of interviewees, the eight and the eleven year olds, consciously acknowledged that competition motivated them and pushed their domestication efforts.

Interviewees at the upper secondary school C favoured the Stanley Parable and Byen. As previously stated, The Stanley Parable originated as a commercial game, while Byen is an educational game. Both are category 2 assemblages; exploration games. Both games were the subject of unanimous positive comments from the pupils. How was the domestication of these exploration games motivated and evaluated?

Casper had played the Stanley Parable at home before it was introduced at school. Like his classmate Carina, he particularly liked 'doing the opposite' of what the narrator voice dictated. "Because then different things happen and-yes (smiles)". Another classmate, Christian, preferred Byen and claimed to have "learned a great deal about social topics, about politics and how it works." Carl, who also favoured Byen, explained:

One gets to experience that one can, like, not just build everything you want, one has to think about the needs of the inhabitants and think about the economy and how the taxes should be. Should they be high or low? Should one go for residential areas or industry?

Caroline reported that she had "learned more from the game than sitting and looking at a book, trying to picture things", placing Byen in the specific context of another component of the learning assemblage-books.

Thus, the upper secondary school pupils had a reflexive relationship to DGBL and possible gains in learning from digital games. Fun, competition, and welcomed breaks from regular teaching were oft mentioned gains. Another common argument was that 


\section{$\$$}

NORDIC JOURNAL

of Science and Technology Studies

having grown up playing digital games, this was a way of learning with which they were accustomed. Other arguments in support of DGBL were improved concentration, better visualization, a more practical and meaningful learning experience, increased motivation, more effective learning, more control over one's own choices and learning, automatization, preparation for life in a technological and even somewhat game-based society, fun for the teachers, fun for the students and, like Christoffer (age sixteen) put it: "sneaking learning into the fun." We can also see this as articulations of the sense-making with respect to DGBL; it was domesticated by being given primarily positive meaning.

Several of the interviewees in school B mentioned their teacher Balder's young age as a facilitating domestication factor. Bent (age eighteen) argued that his teacher's age made it easier for him to understand his pupils. Beate (age eighteen) felt that it made him eager to motivate them:

I think we use games a lot because our teacher is pretty young and he is, kind of very eager to get us all with him - in the teaching. He wants us to be engaged in what we do and not to think that everything is boring, and just something we must do. Because it's about motivating people and getting everybody to come along. So that the classes will be more fun.

As previously mentioned, only commercial games were used in school B. The fact that some students had already played some of these games in their spare time did not seem to spoil the experience.

Bendik (age eighteen): When you played [the commercial game], focusing on learning, then you saw it, kind of, from a slightly different perspective than earlier, because I remember, when I had played it earlier I had not played the whole thing. But then I had not seen, how should I say it, I had not seen the whole depth. Like when we were meant to focus on the personalities of the characters, and write about it and analyse it in that way, then, well, you saw that there was a much deeper history than what you thought when you just played it on your own.

The pupils also provided some thoughtful insights regarding the concrete learning properties of the non-human agents. Beate said that she felt that making realistic ethical choices in the games Walking Dead and The Last of Us had been her most valuable lesson:

There were some places in the game where we thought that we were doing what was ethically right, because it would result in the best consequences and such, but then it ended ghastly for the character we were trying to help. There was one who got caught in a bear trap, and we were absolutely going to help him and not have him eaten by the zombies, and then in the end we had to cut off his foot-and he bled to death! So you suddenly see that the consequences are not always what you would think, in a way. And that is something you would not have experienced if you had just read about it in a book and you felt that the choices became more independent and that you cared a bit more about and not just "oh, whatever, let's do that".

Thus, we see how the learning context was seen to change the domestication of commercial games. A new set of practices emerges in which playing is embedded in reflection. Thus, the games take on new or added meaning.

The upper secondary school pupils were generally also pleased with DGBL, but some voiced scepticism. For example, some pupils in both schools $B$ and $C$ indicated that even if DGBL offered a pleasant experience it was not a 'serious' teaching method. Its usefulness was thus considered potentially limited. Christian (age sixteen), from school C, summarized this argument the following way:

It's been fun. It's a new way of learning. One does learn a bit from it. But I don't believe that only things like this should be used. I don't think it can teach everything. One's got to have other ways of learning as well.

Benjamin and Bjørg (age eighteen) from school B were the most critical interviewees, but even they acknowledged the potential usefulness of DGBL. Benjamin claimed that DGBL was "not an effective way to learn", "meaningless" and that, considering the learning outcome, it took "too much time". Bjørg agreed:

I kind of think that PCS and games are sort of meaningless, because I don't feel that I learn very much, compared to other ways of teaching. I kind of agree that one can have some ways of teaching that are a bit fun and all, so that people can keep up, but I just felt it may be a bit too much gaming for too long a time. It can become quite uninteresting, in a way.

This shows how domestication of DGBL may be performed with different outcomes, above all resulting in differences in the meaning given to the use of digital games in schools.

The sense-making of DGBL can also be affected by prejudice in regard to the playing of games. For example, some third graders from school A indicated that it was common knowledge that video games could be bad for you. One mother had informed her third grade son that a boy had killed his grandmother because he had played too much GTA. Some of the school D sixth graders claimed to know someone who was 'addicted' to gaming. School $\mathrm{C}$ pupils also provided sceptical references about commercial games as well as subtly hinting at potential negative influences on players' behaviour. In school B, where only commercial games were applied, teachers had apparently initiated discussions on these topics and pupils were generally well aware of negative public discourses surrounding these games. At the same time, they had their own reservations to the stigma that were seemingly based on curriculum literature. While discussing the use of GTA in teaching, Birger 


\section{N}

NORDIC JOURNAL

of Science and Technology Studies

(age eighteen) stated that:

I remember the discussion we had and it was that 'are you effected by a lot of violence in games?' Can it do something to your personality? And then we, well, we read a few articles that [digital games] can function as a kind of a substitute for doing something entirely crazy, right? Rather than just raging around, act it out in a game. It's probably true, I don't know, I haven't noticed it in a game-but you do become a bit more aware of it when you discuss it and play the game.

It remains unclear how and to what extent critical attitudes decisively influenced the domestication of DGBL. School B interviewees, for example, were not convinced that a violent game could actually make somebody become violent.

\section{Conclusion: DGBL domesticated}

The use of digital games as a tool for teaching and learning has been considered a way to engage pupils and make classes more interesting. Although some of the older pupils in this study remained somewhat sceptical, the findings of this paper nonetheless continue to support this claim. Most of the interviewed pupils reported that they were happy with DGBL, not just because it was 'a break' or entertaining, but because they also claimed to learn better from using digital games. As previously noted, there may be some positive bias in the selection of focus group participants. Still, there is little doubt that most pupils appreciated DGBL. They welcomed it as a break from other teaching methods, embraced its motivational properties, and acknowledged diverse learning properties including digital fluency, automatization through repetition (drilling), and reflection. At the same time, many did not consider DGBL a superior teaching method fit to replace all other methods, but called for efficient planning of DGBL to ensure the most effective use of their time.

Thus, there is no doubt that DGBL was domesticated at the schools in this study, resulting in particular practices and sense-making. However, compared to other standard accounts of domestication (e.g., Berker et al., 2006), there were some distinct features of the observed processes. Most significantly, we have seen that the accounts of the domestication of DGBL in the four schools suggest that it was collective and managed. Both teachers and pupils apparently needed to engage and interact. Teachers obviously managed the process, but pupils importantly affected one another, not least of all because they played together. The ensuing practices seemed to vary, in part because the purpose of using DGBL varies. While drilling may be an aim for some, the goal of others is to make students more reflexive. It is clear from the accounts of the interviewed pupils that teachers made an effort to provide a sense of digital games as useful tools for teaching and that they generally seemed to succeed in providing their pupils with meaningful learning experiences. A striking feature of sensemaking as related to the practices accounted for by the pupils was the emphasis on competition. Interviewees from every school mentioned competition as a leading motivation factor, so motivating in fact that it could render a drill/quiz school game compatible with commercial entertainment games in terms of attractiveness as a pastime activity.

It is also interesting to note that DGBL can be employed in many types of classes and that the selection of games appeared to be

idiosyncratic and shaped by the tastes and knowledge of the teachers. Taking into account that the schools in this study are cases of 'good practice', that is, schools in which digital games are already domesticated and accepted, DGBL seems to be reasonably well integrated.

The domestication of DGBL resulted in quite a few different DGBL assemblages. I initially distinguished between the drill/quiz games assemblage, the exploration games assemblage and the commercial games assemblage. Further analysis showed that the DGBL assemblages were more complex because, in addition to the type of game, three other elements were important. These were didactic strategies, playing site, and way of playing (individual, in smaller groups, collectively in the class). The outcome of the domestication processes seemed above all to give the pupils fairly strong motivation to engage in DGBL and a sense-making that represented what could be considered as a fairly educated understanding of the use of digital games in school.

The elementary schools in this study focused on drill/quiz games that were designed for education, while the upper secondary schools were more likely to use commercial and exploration games. School $\mathrm{C}$ was the only school in which more than one game assemblage category was employed. They in fact used a hybrid of all three assemblage categories: drill/quizzes, one exploration game and one (originally) commercial game. School $C$ pupils had recently finished elementary school, in which the drill/quiz assemblage category apparently played a big role, and attending upper secondary school, which seemed more open to the commercial game assemblage, and above all encouraged reflection and discussion rather than drilling.

Scripts are intended to direct domestication. In this study, however, we have seen that domestication may supersede such efforts to afford particular outcomes. This is a fairly common observation from domestication studies (e.g., Sørensen 2006). Here, we observed that the scripts of educational games seemed to be followed quite dutifully whereas the scripts of commercial games were transgressed in that games that were scripted to entertain were used to educate, and games that were scripted for one player were played by groups of pupils. As we saw in the case of The Stanley Parable, a commercial game may shift into an educational (exploration) game. Other commercial games, such as The Walking Dead, were used to help upper 
secondary school students reflect upon ethical questions, which was likely not the original goal of the game designers.

To conclude, this study has provided new insight into how DGBL is being domesticated in Norwegian schools today, including the experience of these practices for the pupils. Pupils were generally positive, supporting affirmative claims about the effects of DGBL. This paper must thus be understood as providing analysis of the pupils' assessments of their experience, identifying and illuminating practices and sense-making related to the use of DGBL. It does provide an assessment of actual learning outcomes.

Furthermore, this paper contributes to extant domestication studies literature by analysing domestication in a setting where a group of actors (pupils) interact in ways managed by a leading actor (the teacher). The study thus contributes an understanding

\section{References}

Akrich, M. 1992. The de-scription of technical objects. In Bijker, W. and J. Law (eds.) Shaping technology, building society: studies in sociotechnical change, 205-224. MIT Press.

Ask, K. 2011. Spiller du riktig?: Tid, moral og materialitet i domestiseringen av et online dataspill. Norsk medietidsskrift 18 (2): 140-157.

Barab, S., P. Pettyjohn, M. Gresalfi, C. Volk and M. Solomou. 2012. Game-based curriculum and transformational play: designing to meaningfully positioning person, content, and context. Computers \& Education 58 (1): 518-533.

Berker, T., M. Hartmann, Y. Punie and K. Ward. 2006. Introduction. In Berker, T., M. Hartmann, Y. Punie and K. Ward (eds.) Domestication of media and technology, 1-8. Open University Press.

Creighton, R. H. January 26, 2012. "lt's not an educational game" (Web log message). Last accessed May 2, 2015.

Creswell, J. W. 1998. Qualitative inquiry and research design-choosing among five traditions. Sage Publications.

Dickey, M. 2007. Game design and learning: a conjectural analysis of how massively multiple online role-playing games (MMORPGs) foster intrinsic motivation. Educational technology research \& development 55 (3): 253-273.

Egenfeldt-Nielsen, S. 2006. Overview of research on the educational use of video games. Digital Kompetanse 1 (3): 184-213.

Gansmo, H. J. 2011. Fun and play in digital inclusion. In Sørensen, K. H., W. Faulkner and E. Rommes (eds.), Technologies of inclusion. Gender in the information society, by 109-128. Tapir Academic Press. of the ensuing dynamics of collective and managed domestication process, possibly with similarity to, for example, workplaces. Such domestication means that individuals (pupils) are confronted with limited options in the development of practices and meaning, not least because they would have to interact (play) with each other (classmates) and thus need to be-to at least some extent-compatible. Moreover, the practices were staged by the leading actor (the teacher). Still, the variation observed in pupils' assessments of game playing evidences a certain extent of freedom with respect to sense-making, even if there is little doubt that the meaning of DGBL was strongly influenced by teachers' educational philosophies, choices of games, and their explanations of DGBL. Domestication theory proved useful to understand such settings, but we have seen the need for some amendments to account properly for domestication processes involving the interaction of actors whose actions are orchestrated.

Gee, J. P. 2007. What video games have to teach us about learning and literacy. Palgrave Macmillan.

Gee, J. P. 2012. Digital games and libraries. Knowledge Quest 41 (1): 6o-64.

Gee, J. P. 2013. The anti-education Era-creating smarter students through digital learning. Palgrave/Macmillan.

Gerber, H. R., S. S. Abrams, A. J. Onwuegbuzie and C. L. Benge. 2014. From Mario to FIFA: what qualitative case study research suggests about games-based learning in a US classroom. Educational Media International 51 (1): 16-34.

Giddings, S. 2007. Plaving with non-humans: digital games as technocultural form. In de Castell, S. and J. Jenson (eds.) Worlds in play: International perspectives on digital games research, 115-128. Peter Lang.

Habgood, M. P. J. 2007. The effective integration of digital games and learning content. PhD diss., University of Nottingham, UK.

Haddon, L. 2011. Domestication analysis, objects of study and the centrality of technologies in everyday life. Canadian Journal of Communication 36 (2): 311-23.

Latour, B. 2003. Is re-modernization occurring-and if so, how to prove it? Theory, Culture \& Society 20 (2): 35-48.

Latour, B. 2005. Reassembling the social: an introduction to actornetwork-theory. Oxford University Press.

Lei, S. A. 2010. Intrinsic and extrinsic motivation: evaluating benefits and drawbacks from college instructors' perspectives. Journal of Instructional Psychology 37 (2): 153-160. 
Liste, L. and K. H. Sørensen. 2015. Consumer, client or citizen? How Norwegian local governments domesticate website technology and configure their users. Information, Communication \& Society 18 (7): $733-746$.

Medietilsynet 2014. Barn og unges ( $9-76$ år) bruk og opplevelser av medier. Last accessed July 15, 2015.

Moreno-Ger, P., D. Burgos and J. Torrente. 2009. Digital games in e-Learning environments: current uses and emerging trends. Simulation \& Gaming 40 (5): 669-687.

McGonigal, J. 2011. Reality is broken: why games make us better and how they can change the world. Penguin.

Óskarsson, P. J. 2010. Democracy and the internet. The theoretical foundations and practical applications. Master Thesis, Iceland University, Reykjavík.

Prensky, Marc. 2006. Don't bother me mom, i'm learning! Paragon House.

Resnick, M. 2004. Edutainment? No thanks. I prefer playful learning. Associatzione Cicita. 1 (1): 2-4.

Schunk, D. H. 2012. Learning theories-an educational perspective, $5^{\text {th }}$ ed., Pearson.

Sigurðardóttir, H. D. I. and R. Munkvold. 2013. The mediatization of digital games for learning-a dual rub-off effect. Paper presented at the $7^{\text {th }}$ European Conference on Games Based Learning, Porto.
Academic Conferences International Limited.

Skancke, L. B. 2013. Mellom problem og nytte: Visjoner for digitale spill som lœringsverktøy. Master thesis, NTNU, Trondheim, Norway.

Sørensen, K. H., M. Aune and M. Hatling. 2000. Against linearity: on the cultural appropriation of science and technology in between understanding and trust. In Dierkes, M. and C. v. Grote (eds.) The public, science and technology, 237-258. Routledge.

Sørensen, K. H. 2004. Tingenes samfunn. Kunnskap og materialitet som sosiologiske korrektiver. Sosiologi i dag 34 (2): 5-25.

Sørensen, K. H. 2006. Domestication: the enactment of technology. In Berker, T., M. Hartmann, Y. Punie and K. Ward (eds.) Domestication of media and technology, 40-61. Open University Press.

Steinkuehler, C. 2010. Digital literacies: video games and digital literacies. Journal of Adolescent \& Adult Literacy 54 (1): 61-63.

St. meld. no. 14 (2007-2008). 2008. Dataspill. Kultur- og kirkedepartementet.

Taylor, T.L. 2009. The assemblage of play. Games and culture 4 (4): 331-339.

Van Eck, R. 2006. Digital game-based learning: it's not just the digital natives who are restless... EDUCAUSE review 41 (2): 17-30.

Whitton, N. 2010. Learning with digital games: a practical guide to engaging students in higher education. Routledge. 